\title{
Power and Politics of User Involvement in Software Development
}

\author{
Muneera Bano \\ Swinburne University of Technology \\ Melbourne, Australia \\ mbano@swin.edu.au
}

\author{
Didar Zowghi \\ University of Technology Sydney \\ Sydney, Australia \\ Didar.Zowghi@uts.edu.au
}

\author{
Francesca da Rimini \\ University of Technology Sydney \\ Sydney, Australia \\ Francesca.da.Rimini-1@uts.edu.au
}

\begin{abstract}
[CONTEXT] Involving users in software development is a complex and multi-faceted concept. Empirical research that studies power and politics of user involvement in software development is scarce. [OBJECTIVE] In this paper, we present the results from a case study of a software development project, where organizational politics was explored in context of user involvement in software development. [METHOD] We collected data through 30 interviews with 20 participants, attending workshops, observing project meetings, and analysing projects documents. The qualitative data was rigorously and iteratively analyzed. [RESULTS] The results indicate that the politics was a significant factor used to exert power and influence in decision-making processes. Communication channels were exploited for political purposes. These contributed to the users' dissatisfaction with their involvement thus impacting on the project outcome. [CONCLUSION] Having multiple teams of stakeholders with different levels of power in decision-making, the politics is inevitable and inescapable. Without careful attention, the political aspect of user involvement in software development can contribute to unsuccessful project.
\end{abstract}

\section{Categories and Subject Descriptors}

D.2 [Software Engineering]: D.2.9 Management

\section{Keywords}

Power, Politics, User Involvement, Software Development

\section{ACM Reference format:}

M. Bano, D. Zowghi, F. da Rimini. 2018. In Proceedings of Evaluation and Assessment in Software Engineering, Christchurch, New Zealand June 2018 (EASE). https://doi.org/10.1145/3210459.3210477

Permission to make digital or hard copies of all or part of this work for personal or classroom use is granted without fee provided that copies are not made or distributed for profit or commercial advantage and that copies bear this notice and the full citation on the first page. Copyrights for components of this work owned by others than ACM must be honored. Abstracting with credit is permitted. To copy otherwise, or republish, to post on servers or to redistribute to lists, requires prior specific permission and/or a fee. Request permissions from Permissions@acm.org.

EASE'18, June 28-29, 2018, Christchurch, New Zealand (C) 2018 Association for Computing Machinery. ACM ISBN 978-1-4503-6403-4/18/06 ..\$15.00 https://doi.org/10.1145/3210459.3210477

\section{INTRODUCTION}

User involvement (UI) in software development (SD) has been studied extensively for more than four decades [1-4]. Many early researchers considered it axiomatic that user involvement has direct positive influence on successful outcome of the system [4]. However, aggregated empirical literature shows conflicting results [1-3]. A deeper analysis of the empirical research on 'user involvement and system success (UI-SS)' relationship has shown that it is not a simple binary relationship, and that there are various confounding variables that play their role in a convoluted way to contribute to the success or failure of a software system $[3,5]$. Defining the term ' $u$ ser' is contextual for any specific software project [25], however, a user is typically considered to be someone who would be actually using the system and can play various roles on different levels in an organization or a team [1].

The UI-SS relationship has been studied from various perspectives such as psychological [3, 6], managerial [7], political [8], cultural [9], or methodological [10]. The studies focusing on political and cultural aspects of UI were more uncertain about the positive outcomes of UI-SS relationship [1, 24]. The degree of power given to users during their project involvement will undoubtedly determine their extent of influence on the outcomes $[11,12]$. The level and degree of involvement can be affected by organizational or political influence especially when it comes to power of decision-making and change implementation [13, 27]. Politics in organizations is inevitable when multiple stakeholders with different interests and levels of power are involved in decision-making [14].

In a social context, Power is an attribute of an individual and can be observed within a relationship or interaction of two or more individuals [13]. Power provides an individual with the ability to influence behavior of others [15]; (either make them do something they wouldn't otherwise, or prevent them from doing something that they would like to do), or by defining reality for others to act accordingly [16]. An individual can have different types of power e.g. legitimate, coercive or knowledge [17]. However, power of an individual can only be observed through the actions. Channeling the power possessed by an individual into actions and acting upon it in a social interaction is Politics. According to Milne and Maiden [13], one demonstrates Power in a social group through practice such that it "can be analyzed by looking at the structure of relationship between individuals" and the Politics is observed in actions of "decision-making processes involving these individuals".

The political aspect within information systems literature has focused more on the factors in organizational change, managerial 
practices, and deliberate sabotage through political tactics to resist change $[18,19,27]$. Ives and Olson defined the power of users as " "the amount of influence the user has over the final product" [4]. They have classified the power of user based on the degree of UI on a spectrum from "No involvement" to "Involvement by strong control". Enid Mumford [12] and Damodaran [11] explained the power of users based on their level of involvement in SD and influence on decision-making: i.e. consultative, representative and consensus. User involvement has been considered as a democratic step towards empowering users, by giving them the ability to influence decisions and get a sense of control and ownership of the software system $[9,26]$. However, UI can create conflicts due to the misalignment of the expectations between users and developers; about the level and degree of UI in the project and the extent the users can influence the decisions and outcomes [28]. In software engineering literature, few studies have attempted to investigate the power and politics in various domains such as requirements engineering [13, 20], and software eco-systems [21-23]. However, the empirical literature within the context of UI-SS relationship has largely ignored political aspects.

In this paper, we present the results of a case study, where the political aspect of UI-SS relationship was perceived to have played a crucial role in contributing to "user dissatisfaction" and hence exerting a negative influence on the project outcome. Our case study was guided by the overarching research question: How does organizational power and politics influence user involvement in software development? Major contributions of the research reported in this paper are:

- Empirical study of organizational politics of user involvement in software development

- New findings that contribute to the body of knowledge on existing evidence on UI-SS relationship

The paper is structured as following: Section 2 provides details of case study including data collection and analysis; section 3 discusses the results; section 4 describes the limitations of the case study and section 5 provides the conclusion and future directions.

\section{CASE STUDY}

Our case study was conducted in a large financial institution of one of the State Government Organizations (SGO) ${ }^{1}$ in Australia. SGO initiated the implementation of a number of process improvements projects in 2012, as part of the preparatory work for a very large national digitization project. Hence, SGO created a 'Digitization Readiness' project to achieve the systems and process changes, and ensure that they will be ready for transition. The SGO had both a complex hierarchal structure as well as relationships with other public sector organizations and government agencies. Our research participants were public servants working for SGO, who in many cases had been employed for anywhere between 1-4 decades. Some of the key characteristics of SGO in this case study were: a) Software was being developed internally with almost no external consultants or developers involved, b) Waterfall software

${ }^{1}$ The name of this organization and acronym is fictitious due to ethical considerations and non-disclosure agreement. development process was employed with two distinct builds, c) Bespoke software, d) SGO had a very large IT department with complex governance structure, e) too many stakeholders both internally and externally; e.g. 5 software companies who are web developers as external stakeholders, f) Several factors external to SGO impacted the project; e.g. scope was substantially reduced due to Government cuts, g) Most employees we interviewed had been at SGO for a long time on average $10+$ years, h) Project Manager had enormous power and authority, i) No formal review process took place throughout the project, but rather mainly informal passing of documents to key decision makers to comment, $\mathrm{j}$ ) Organization-wide confusion over roles and responsibilities.

Our case study was exploratory and interpretive in nature [29]. In the interpretive research paradigm the role of researcher is challenging in order to observe, understand and analyze the interpretations of empirical data as reported based on the experiences of the people. To ensure the credibility of our research in the interpretive paradigm, we collected data from multiple sources (i.e., data triangulation). We used an iterative analytical approach, including emails and follow up interviews with the case study participants, to confirm our interpretation of the data. Our case study research spanned over two years. Our data set included transcribed interviews with stakeholders, our own observational notes while attending relevant workshops and meetings, as well as a review of formal project documentations provided. Although the data was collected about many aspects of user involvement, in this short paper we only focus on the political aspect of user involvement captured in our data analysis.

As our research focused on users' subjective perceptions and experiences of their involvement in the SD life cycle, we used structured interviews with a broad sample of various kinds of users and stakeholders as our primary data collection method. This was complemented by periodic on-site observation of steering committee meetings, workshops and training sessions, along with review and analysis of key documents.

Document analysis. During the data collection phase the Project Manager (PM) periodically provided us with relevant documents for review. In total, we received 25 documents. Many of these mainly aimed to serve the organization's administrative requirements, and hence their contents were often high-level and did not directly contribute to answering our research question. However, they did indicate some of the organization's structural and communicational processes that helped us develop many of our emerging insights.

Interviews. Interviewee selection was determined by suggestions from key stakeholders and users within the organization. In the first instance the Chief Information Officer (CIO) arranged for the second author to interview the PM, who then selected and scheduled interviews with an initial cohort of subjects. As requested, these subjects comprised various categories of stakeholders and users including senior bureaucrats, one regional manager, local team leaders, business analysts, Subject Matter Experts, programmers, end users, and trainers. Each interview 
lasted on average 40-60 minutes, and was digitally audio recorded. Following preliminary conversations with the PM and review of the requirements and project planning documents, we conducted two stages of interviews. As the organization had undertaken requirements gathering, and also had developed and released Phase 1 of the software, our first stage of interviews coincided with development of requirements for the Phase 2 release, internal User Acceptance Testing, and processes related to emerging change management issues. The second stage of interviews occurred after the software's final release to internal users. We conducted 30 interviews with 20 participants, mainly recorded in face-to-face settings; this included some brief follow-up phone interviews for clarification purposes, and a few face-to-face discussions which were not digitally recorded. Overall, 13 subjects were interviewed once, 6 subjects were interviewed twice, and 1 subject (the PM) was interviewed 5 times. We used two slightly different sets of interview questions ${ }^{2}$ for the interviews in Stage 1 of the data collection. The first set (comprising 20 questions) was tailored to elicit responses from a broad range of stakeholders and users. The second set (comprising 22 questions) addressed the role of business analysts in the project. Responses by interviewees helped guide the interview questions for Stage 2 of the data collection. By this time one researcher had performed the first stage of data analysis, and two researchers had together reflected on emerging themes from the first round of qualitative data analysis.

Observation. As requested, the PM arranged for us to attend various periodic and one-off events related to the software project. We attended 4 project meetings, of which 3 were Steering Committee Meetings, and 1 was a Requirements Review Meeting. We also attended 1 workshop, and 1 software training session. During the meetings and workshop we used an ethnographic approach to data collection. First, we identified the attendees and their organizational role. Second, we took extensive handwritten notes of observed interactions between attendees. Third, we wrote up our reflections immediately following each event, focusing on the roles specific attendees appeared to play, their individual communication styles, the facilitator's communication style and presentation methods, and users' expressions of positive and negative affects about the software development project (SDP) and how it was being conducted. In the final stage of our data analysis we reviewed these reflections, identifying whose voices that had been the most prominent, which issues they had raised as concerns or criticisms, and whether they had expressed similar concerns during our individual interviews.

2.2.2 Data Analysis. First, the audio interviews were professionally transcribed after which we used NVivo for coding the data against the subjects of the interview questions and thematic analysis. As more themes emerged during the coding process, more nodes and sub-nodes were added to the analytical schema in NVivo. These thematic categories highlighted the complex nature of software development and implementation, and the many technical and social interdependencies at play. In total, we coded the data against a possible 86 themes on which to perform the next stage of analysis, comparing and contrasting individuals' perceptions of the software project. Such a fine-grained analysis provided us with an extremely rich data set from which to identify patterns, trends, points of comparison and areas of potential conflict.

In order to understand how politics manifested in UI-SS relationship, we were focusing on the power held by different people within organization. To determine in whom power resided and how they exercised their power, we analyzed participants' comments about who made crucial decisions about project personnel, budgets and time-frames. To better understand the power dynamics operating between various parties, we looked at if and how users and stakeholders had challenged contentious decisions and processes, and how those in authority had responded. We noted when people expressed feeling frustrated and/or powerless to draw attention to, or mitigate, software-related technical problems affecting business processes; such accounts indicated that these individuals held a relatively lesser degree of agency in the SDP. Finally, we revisited what people had said about their own and others' roles in the project in terms of decisionmaking, delegation and authorization powers. In some cases, perceptions made by one respondent were echoed by a number of others. In other cases, experiences of involvement or the project outcome would dramatically differ amongst subjects, often it would seem according to the user's role in the project. We used such points of comparison and contrast to develop insights.

\section{RESULTS AND DISCUSSION}

To answer our research question, the analysis of case study data revealed that intra-organizational politics resulted in dissatisfaction of users about their involvement in the SDP. In previous studies [25], the satisfaction of users with the process of their involvement has been observed to be mutually constituted with their satisfaction with the product (system). In our case study, we observed the similar phenomenon; the users were dissatisfied with their involvement and this contributed to their dissatisfaction about the project outcome (product/system). The nexus between Power and Politics within UI-SS relationship was observed to have influenced both the process of UI (causing dissatisfaction, frustration and conflicts) and the product (system was significantly over schedule and over-budget). The unique nature of the project along with the ineffective role played by PM and SME, provided an opportunity for people to indirectly influence the decisions and outcomes of the project to meet the interests of their divisions. Modes of communication that either excluded users, or included them only nominally, generated or cemented many users' perceptions that they had little real say in the SDP. The users voiced their concerns about lack of consultation and ineffective communication. In this section, we summarize our results to point out the factors from political aspect that contributed to users' dissatisfaction and project outcome.

\footnotetext{
${ }^{2}$ https://drive.google.com/file/d/0B8AfnftYIxYDd2FVcFJqSGdPSzg/view
} 


\subsection{The Different Levels and Types of Power}

In the context of SDP, politics was manifested through the power to influence the product (software), and the process (decision-making, user involvement). Those with power can exert control over people and resources. In this software project, people include the development team, programmers, stakeholders and users, and resources primarily financial (budget allocations) and temporal (schedules); People, money and time. Figure 1 shows the organizational communication structure and the interactions of different people from business unit and development team. Note in Figure 1 we have selected those subjects whose interview transcripts were directly relevant to political aspect of user involvement. Our analysis revealed that from our pool of 20 interviewees, 8 people appeared to hold different kinds of power in this project. Furthermore, we found that many participants regarded the SDP team to be a powerful entity in its own right. We have aggregated the results of transcript analysis of BA, Senior BA and Senior Developer into "Software Development Team" to present a coherent narrative from development team perspective. Below we discuss the selected examples of the people who were considered powerful to influence the SDP.

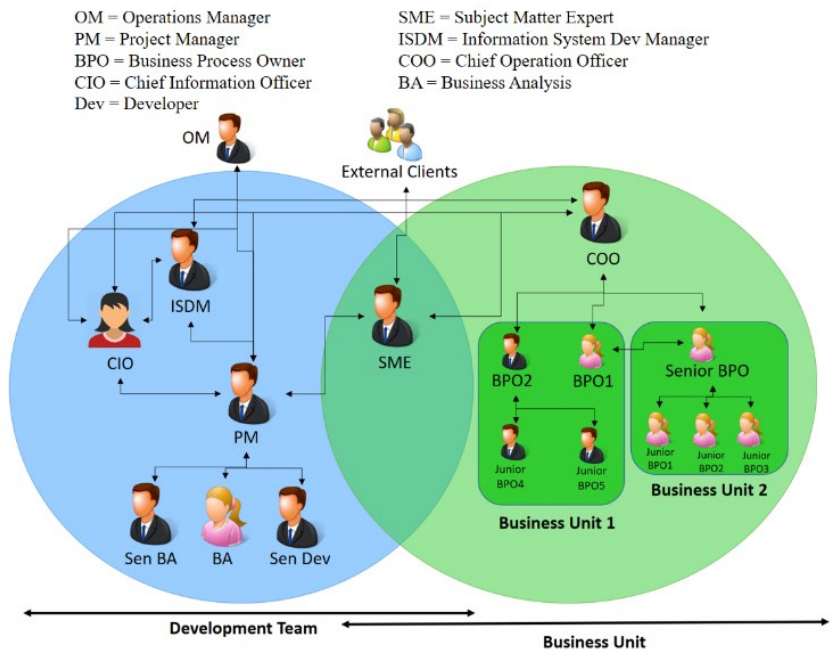

Figure 1: Organizational structure showing key actors

1. Project Manager (PM): There was consensus amongst participants that the PM ran the show, and was responsible for the technical and social processes underpinning the product's development. He had "developed the business case which was put forward for consideration", according to the CIO. The COO had then authorized the PM to recruit his own team, mainly seconded SGO employees, and thus he had power over his team members from the outset; the exception was the SME whom the BPO1 had chosen. From the CIO's view, this power was somewhat problematic because "a lot of the project budget has been used to fund people at higher salaries than they would ordinarily get paid"; furthermore, the PM had been "acting in a role four grades higher than his substantive role...for a number of years".
2. Subject Matter Expert (SME): The data suggests that the SME had power to influence both the SDP product and processes. Knowledge is power, especially perhaps in a bureaucracy, and noone had any doubts as to the SME's expertise. A tight bond appeared to exist between the PM and the SME, men of a similar age who had been SGO employees for decades. The SME enjoyed unqualified support from the PM who described him as "just an ideal person to have on board... he knows everything there is to know about anything related to [business area]". This trust in the SME's 'exhaustive knowledge' and his ability to "make sure that we are actually getting the [requirements] definition right in terms of the functional spec" might explain the PM's disinterest in conducting more inclusive project communications throughout the development life cycle. He had his expert in the inner circle and did not invite other views. Thus, the SME's power was accorded and maintained by the PM.

3. Business Process Owner 1 (BPO1): A senior manager who had been an SGO employee for many decades had the role of Business Process Owner (BPO) and co-sponsor on this SDP. She wielded substantial power over project processes. In the first instance, she had engaged the PM and the SME. The ISDM assumed that she had decided all SDP team appointments herself "as she may see fit in terms of their experience, their knowledge within that area". This demonstrates the lack of transparency in project decisions and lines of power, but perhaps those higher up in the bureaucracy did not consider it important to communicate such things. As Project Owners, the BPO1 and the $\mathrm{COO}$ could "pretty much determine who they feel is most appropriate for the Steering Committee", the PM explained, and so they selected representatives from ISD, the Project Management Office and Business.

4. Senior Business Process Owner: 'Senior Business Process Owner' SBPO worked at a high level in operations at SGO. She was a long-term employee who had worked in both IT and Business, and had hands-on experience with waterfall and agile methodologies. Quite a few of SGO personnel complained about the project, but only SBPO reported being so dissatisfied that she took steps to have her team's concerns heard and actioned. For this reason, we consider that she held enough power to influence both the SDP's product and processes. At the heart of her expressed frustration with the conduct of the SDP was the issue of communication: "When we tend to do projects off to the side...I'm sort of acknowledged as a stakeholder but not really consulted on a lot of that stuff". So here we have one person's snapshot of part of the power structure of the project: internal and external counterparts whom the SDP team had to keep in the loop, a highlevel management team who expected reports, and those whom the SDP team felt no obligation to brief.

5. Operations Manager (OM): The Operations Manager (OM) was on the Steering Committee, and regarded himself as being able to influence both the product and some processes, and also the larger software project (national digitization), the SDP would be migrating to. He had been "providing [PM] with information, to see what we can do to get this work done in any way, shape or form". One measure of someone's power in this case study is their ability to achieve things by direct communications, especially face- 
to-face situations, rather than by long email discussions or attendance at Steering Committee meetings. Moreover, OM positioned himself (to us) as someone able to influence other divisions.

6. Information System Development Manager (ISDM): We noted discrepancies amongst how ISDM described his role and influence in the SDP, and how some others saw it. According to OM, ISDM was "in a very difficult position, he's only new to [SGO], he has an uncooperative director". In SGO where many had been employed for decades, we can imagine that someone who had been there for a few months would face challenges to their understanding of how things were done, how power operated, and how decisions were influenced.

7. Chief Information officer (CIO): The CIO had been employed at SGO for less than 2 years. Although in theory she had concrete connections and responsibilities to the SDP via at least 2 Boards and Committees, in reality it appeared that she was uncertain about how the project functioned in practice, especially in regard to power and decision-making processes. We conclude therefore that her influence on the project's conduct and product was initially limited but it gathered momentum as we witnessed her impact in a Steering Committee meeting.

8. Chief Operation Officer (COO): The COO described his 'prime role' in the SDP as the "overall steering of the project and funding". He had the kind of hands-off approach that typifies this high level of managerial power, and therefore we could not see that he influenced whether the project's product or processes. At least the OM thought that the COO possessed more power in the project than he chose to exercise, in relation to the provision of IS resources. It appears that the $\mathrm{COO}$ preferred to joining forces with the $\mathrm{CIO}$ to effect more strategic organizational change, and therefore elected to stay out of the fray of the SDP.

9. Software Development Team: For some high and mid-level managers the project team was a discrete social entity headed by strong personalities who made their stamp on project processes. Unusually for SGO the project was located in the business environment, rather than in the information systems department, so team members had the advantage of working in a familiar environment rather than being 'upstairs' in an IT department of around 65 people. The team built a strong reputation with upper management. Various participants recognized the development team to have more power to influence the product than it should. The CIO said that the project "sort of had a life of its own" when she started at SGO. When a project becomes almost human, power becomes more abstract, cloaking those who wield it. This tendency to separate power from its individual human sources can make it harder to question or contest it.

We observed that the participants of SDP in this case study held different degrees and levels of power to influence the project directly or indirectly. A direct influence comes from the "legitimate power" [17] that gives one formal authority to make decisions. In our case study there were multiple people with "legitimate power" to either make decisions, or to influence others' decisions e.g. PM, $\mathrm{COO}, \mathrm{OM}$, and BPO1. Although the $\mathrm{COO}$ had direct power, he adopted a hands-off approach, which in part might be attributable to the short duration he had been employed by SGO in comparison to those who were answerable to him. The BPO1 used her power to remedy some of the communication problems, by eventually insisting that SBPO was included in communications, although this happened in response to SPBO's complaints.

An indirect influence is exerted by either "expert power" or "referent power" [17]. An "expert" is someone who possess higherlevel skills or knowledge (technical or business domain) that are needed by the organization. An individual with "referent power" is someone with higher levels of interpersonal skills, such as communication or negotiation, which can win arguments and build loyalties. In our case study, SBPO is the epitome of indirect influence through social interaction, being technically savvy and having business knowledge. Her extreme dissatisfaction with many aspects of the project, including the lack of a change management plan, led her to employ new lines of communication between her team and the developers. The $\mathrm{OM}$ is an example of indirect influence by being an excellent communicator We observed that the indirect influence by SBPO and OM contributed to the politics and thus overriding some decisions made by those with 'legitimate power'.

\subsection{Communication Issues}

In this case study, the majority of the problems emanating from people with different power, and the organizational politics, were communication-related. We identified five recurring categories in the transcripts and our observation notes related to communication issues: ineffective communication, lack of communication, vague or unidentified software project-related communication roles and responsibilities, lack of communication of the big picture to users, and lack of consultation. In order to influence the decisions, the key-power-players were observed to exploit the communication process. Whether it was withholding information, or ineffective communication, the issues in communication were observed to have caused frustration and dissatisfaction among the users about their involvement in the project. It is important to remember that some of the most powerful people in this project had been with the organization for decades, and hence their modes and habits of communication in the SDP are likely to also reflect broader aspects of intra-organizational and inter-organizational power, and how people used the project to maintain their professional positions within a highly bureaucratized and segmented SGO.

\subsection{Ineffective Role Played by PM and SME}

We heard many criticisms and negative comments in interviews about the roles played by, and influence of, the PM and SME in the project. Overall, the management strategy adopted by the PM was perceived to be ineffective in resolving the concerns of the users throughout the project. The communication between the PM and BPOs was judged to be vague and ineffective as we presented in the results section. The PM had complete trust in the SME and his ability to represent the users' voice and needs in the SDP which gave SME too much power to navigate and lead the design of the system to what he alone judged to be needed. There was no evidence that we could observe about SME holding any meaningful 
consultation with any users' groups and BPOs in SGO about their real needs for the system. Nor did he share his knowledge of where the SDP was heading with any of them. He was entrusted by the SGO to represent the BPOs and users in the SDP and to safeguard their interests. Our observation of his attitude and conduct in this project did not comply with what we consider as best practice in SD. In summary, the PM and SME together adopted an undemocratic approach which nullified the whole purpose of user involvement.

\section{Limitations of our study}

In regards to our qualitative research under constructivist paradigm of inquiry, it is impossible for us to claim absolute exactness of the results to be free from researchers' bias. Moreover, the case study research methodology is inherently reliant on researchers' inductive reasoning capabilities and expertise of researchers (which might include also their own biases). We concede that there are also limitations to the data collection process that were not in our control. The selection of participants was constrained by the referral of PM in this case study. The complex nature of the project was reflected in the collected qualitative data with lot of confusion and contradictions in the responses of the interviewees. The project had a unique context as described in section 2 . This made the data analysis phase quite challenging and time consuming for the researchers. To address the limitations of the case study, we have provided full details of the context in which we analyzed the data. For confirmation and required clarification of concepts, we discussed the understanding we developed from the findings of previous interviews with the respondents.

\section{Conclusion and Future Work}

In this paper, we have presented the results of a case study to investigate the power and politics within the context of UI-SS relationship. We analyzed qualitative data from interviews, observations and documents to investigate power and politics of user involvement in SD. Our analysis has revealed that organizational politics can contribute to user dissatisfaction about their involvement, thus negatively influencing the project outcomes. In our case study we have observed that power was exercised directly or indirectly to influence decisions. Due to ineffective communication by those with legitimate power, it was easier for different team members to exploit the modes of communication for political purposes. With lack of effective and dynamic management of UI, the indirect use of power, that overrides legitimate authority, can steer the project in a different direction to the one intended. User involvement is a complex phenomenon. It is a double-edged sword and without effective and dynamic management strategies, can cause serious problems in achieving the goals in SD projects. The degree and extent of user involvement in SD projects needs to be carefully planned and managed. Finally, having a seat at the table is not the same as having a voice; having a voice is not the same as being heard; being heard is not the same as having influence on the outcomes.

We are currently in progress on analyzing the rich qualitative data from the case study to categorize the types of power held by all the participants in our case studies and map them to the classification proposed in [17] through social network analysis.

\section{REFERENCES}

[1] Bano, M. and D. Zowghi, A systematic review on the relationship between user involvement and system success. Information and Software Technology, 2015. 58: p. 148-169.

[2] Abelein, U. and B. Paech, Understanding the influence of user participation and involvement on system success-A systematic mapping study. Empirical Software Engineering, 2015. 20(1): p. 28-81.

[3] Cavaye, A.L., User participation in system development revisited. Information \& Management, 1995. 28(5): p. 311-323.

[4] Ives, B. and M.H. Olson, User involvement and MIS success: A review of research. Management science, 1984. 30(5): p. 586-603.

[5] Zowghi, D., F. da Rimini, and M. Bano. Problems and challenges of user involvement in software development: an empirical study. in Proceedings of the 19th EASE 2015. ACM.

[6] Baronas, A.-M.K. and M.R. Louis, Restoring a sense of control during implementation: how user involvement leads to system acceptance. MIS Quarterly, 1988: p. 111-124.

[7] Wagner, E.L. and G. Piccoli, Moving beyond user participation to achieve successful IS design. Communications of the ACM, 2007. 50(12): p. 51-55.

[8] Robey, D. and D. Farrow, User involvement in information system development: A conflict model and empirical test. Management science, 1982. 28(1): p. 7385 .

[9] Iivari, N., 'Representing the User'in software development - a cultural analysis of usability work in the product development context. Interacting with Computers, 2006. 18(4): p. 635-664

[10] Muller, M.J., J.H. Haslwanter, and T. Dayton, Participatory practices in the software lifecycle. Handbook of human-computer interaction, 1997. 2: p. 255297.

[11] Damodaran, L., User involvement in the systems design process-a practical guide for users. Behaviour \& information technology, 1996. 15(6): p. 363-377.

[12] Mumford, E., Consensus systems design: An evaluation of this approach. Design and Implementation of computer based information systems, 1979.

[13] Milne, A. and N. Maiden, Power and politics in requirements engineering embracing the dark side? Requirements Engineering, 2012. 17(2): p. 83-98.

[14] Maiden, N., Politics Are Inescapable. IEEE software, 2012. 29(5).

[15] Dahl, R.A., The concept of power. Systems Research and Behavioral Science, 1957. 2(3): p. 201-215

[16] Bachrach, P. and M.S. Baratz, Two Faces of Power. Power: Critical Concepts, 1994. 2: p. 85.

[17] French, J.R., B. Raven, and D. Cartwright, The bases of social power. Classics of organization theory, 1959. 7.

[18] Grover, V., A.L. Lederer, and R. Sabherwal, Recognizing the politics of MIS Information \& Management, 1988. 14(3): p. 145-156.

[19] Markus, M.L., Power, politics, and MIS implementation. Communications of the ACM, 1983. 26(6): p. 430-444.

[20] Johann, T. and W. Maalej. Democratic mass participation of users in Requirements Engineering? in Requirements Engineering Conference (RE), 2015 IEEE 23rd International. 2015. IEEE.

[21] Valença, G. and C. Alves, A theory of power in emerging software ecosystems formed by small-to-medium enterprises. Journal of Systems and Software, 2017. 134: p. 76-104.

[22] Hurni, T. and T. Huber, The interplay of power and trust in platform ecosystems of the enterprise application software industry. 2014.

[23] Poo-Caamaño, G., Release management in free and open source software ecosystems. 2016.

[24] Bano, M. and D. Zowghi. User involvement in software development and system success: a systematic literature review. in Proceedings of the 17th EASE 2013. ACM.

[25] Bano, M., D. Zowghi, and F. da Rimini, User satisfaction and system success. an empirical exploration of user involvement in software development. Empirical Software Engineering, 2017. 22(5): p. 2339-2372.

[26] Kujala, S., Effective user involvement in product development by improving the analysis of user needs. Behaviour \& Information Technology, 2008. 27(6): p. 457-473.

[27] Bjerknes, G. and T. Bratteteig, User participation and democracy: A discussion of Scandinavian research on system development. Scandinavian Journal of information systems, 1995. 7(1): p. 1.

[28] Buchan, J., et al. Alignment of Stakeholder Expectations about User Involvement in Agile Software Development. in Proceedings of the 21st EASE 2017. ACM.

[29] Walsham, G., Doing interpretive research. European journal of information systems, 2006. 15(3): p. 320-330. 